\title{
Excision of Nonpalpable Breast Cancer with Indocyanine Green Fluorescence-Guided Occult Lesion Localization (IFOLL)
}

\author{
Fatih Aydogan Volkan Ozben $^{\mathrm{b}} \quad$ Erman Aytac $^{\mathrm{a}} \quad$ Halit Yilmaz $^{\mathrm{c}}$ \\ ${ }^{a}$ Department of General Surgery, Istanbul University Cerrahpasa Medical School, Istanbul \\ ${ }^{b}$ General Surgery Clinic, Surmene State Hospital, Surmene, Trabzon, \\ 'Department of Radiology, Istanbul University Cerrahpasa Medical School, Istanbul, Turkey
}

Ali Cercel ${ }^{\mathrm{a}} \quad$ Varol Celik $^{\mathrm{a}}$

\section{Keywords}

Nonpalpable cancer · Breast · Indocyanine green fluorescence imaging · Lesion localization · Excision

\section{Summary}

Background: Currently employed techniques for the localization of nonpalpable breast lesions suffer from various limitations. In this paper, we report on 2 patients in order to introduce an alternative technique, indocyanine green fluorescence-guided occult lesion localization (IFOLL), and determine its applicability for the surgical removal of this type of breast lesions. Case Reports: Preoperatively, one of the patients had a needle biopsyproven diagnosis of breast cancer, and the other one had suspicious findings for malignancy. Lesion localization was performed within $1 \mathrm{~h}$ before surgery under ultrasonography control by injecting $2 \mathrm{ml}$ and $0.2 \mathrm{ml}$ of indocyanine green into the lesion and its subcutaneous tissue projection, respectively. During surgery, the site of skin incision and the resection margins were identified by observing the area of indocyanine-derived fluorescence under the guidance of a near-infrared-sensitive camera. In both cases, the breast lesion was correctly localized, and the area of fluorescence corresponded well to the site of the lesions. Subsequent surgical excision was successful with no complications. On histopathologic examination, the surgical margins were found to be clear. Conclusion: IFOLL seems to be a technically applicable and clinically acceptable procedure for the removal of nonpalpable breast cancer.

\section{Schlüsselwörter}

Nicht palpable Tumoren - Mamma .

Indocyaningrün-Fluoreszenzbildgebung ·

Läsion Lokalisation · Resektion

\section{Zusammenfassung}

Hintergrund: Derzeit angewandte Verfahren zur Lokalisation nicht palpabler Mammakarzinome unterliegen verschiedenen Limitationen. Der vorliegende Bericht umfasst die Fälle zweier Patientinnen, anhand welcher ein alternatives Lokalisationsverfahren basierend auf Indocyaningrün-Fluoreszenzbildgebung (indocyanine green fluorescence-guided occult lesion localization, IFOLL) vorgestellt und seine Anwendbarkeit für die chirurgische Entfernung von nicht palpablen Mammakarzinomen geprüft werden soll. Fallberichte: Im Rahmen der präoperativen Diagnostik war bei einer Patientin ein durch Nadelbiopsie bestätigtes Mammakarzinom festgestellt worden. Bei der zweiten Patientin bestand der Verdacht auf eine maligne Tumorerkrankung. Die Tumorlokalisation wurde unter Ultraschallkontrolle in der Stunde vor der Operation durch Injektion von $2 \mathrm{ml}$ bzw. 0,2 ml Indocyaningrün in die Läsion bzw. das umgebende subkutane Gewebe durchgeführt. Während der Operation wurden der Hautschnitt bzw. die Resektionsränder durch Darstellung der Indocyanin-Fluoreszenz mittels einer Nahinfrarotkamera identifiziert. In beiden Fällen wurde die Mammaläsion korrekt lokalisiert, und der Fluoreszenzbereich korrespondierte gut mit dem Tumorbereich. Die anschließende chirurgische Resektion verlief erfolgreich und ohne Komplikationen. Die histopathologische Untersuchung zeigte saubere Resektionsränder. Schlussfolgerung: IFOLL scheint eine technisch durchführbare und klinisch akzeptable Methode zur Entfernung nicht palpabler Mammakarzinome zu sein.

\section{KARGER \\ Fax +497614520714 \\ Information@Karger.de}

www.karger.com (c) 2012 S. Karger GmbH, Freiburg

1661-3791/12/0071-0048\$38.00/0

Accessible online at:

www.karger.com/brc
Volkan Ozben, M.D

Surmene Devlet Hastanesi

Genel Cerrahi Klinigi

PO Box: 61600, Surmene, Trabzon, Turkey

Tel. +90 46274614-22, Fax -29

volkanozben@yahoo.co.uk 


\section{Introduction}

The widespread use of breast screening programs has increased the diagnosis of nonpalpable breast lesions and, as a consequence, improved the detection of occult breast cancers. Precise localization of these lesions prior to surgical removal is mandatory [1]. Traditionally, surgical excision of this kind of lesion has been carried out with several techniques such as carbon localization, wire insertion, and intraoperative ultrasonography (US); however, each technique suffers from various limitations [1-3]. As an alternative technique, radioguided occult lesion localization (ROLL) has emerged as a better option for targeting these lesions [1-4]. With the aid of developing technology, further advances have been made in breast surgery, and subsequently, a novel technique using fluorescence imaging of indocyanine green (ICG) dye has been described [5]. To date, the published studies on this technique have assessed its role for the identification of sentinel lymph nodes as an alternative to radio-guided surgery [69]. Yet, this technique has never been utilized as an adjunct to the excision of nonpalpable breast lesions. In this paper, we report on 2 breast cancer patients in order to introduce a new technique, ICG fluorescence-guided occult lesion localization (IFOLL), and determine its role for the identification and excision of such breast lesions.

\section{Case Reports}

\section{Case 1}

A 72-year-old woman presented to our clinic with an occult breast lesion which was noticed during her annual breast screening program. Mammography showed a stellate lesion with increased density in the inner lower quadrant of her left breast. Breast examination was normal and neither a mass nor axillary lymphadenopathy was detected. US demonstrated this lesion as a deeply located hypoechoic mass measuring $10 \times 0.8 \mathrm{~mm}$ in diameter (BIRADS 5). Core needle biopsy under US revealed invasive ductal carcinoma. Based on these findings, preoperative lesion localization and subsequent surgical excision with sentinel lymph node biopsy were planned. In order to guide sentinel node biopsy, $2 \mathrm{mCi}$ of $99 \mathrm{~m}-\mathrm{Tc}$ tin colloid was injected around the periareolar area 1 day before surgery, and the sentinel node location was confirmed by the lymphoscintigraphic images.

\section{Case 2}

A 46-year-old woman presented with clusters of microcalcifications in the left upper quadrant of her right breast, which were detected on screening mammography. On breast examination, there was neither a palpable mass nor axillary lymphadenopathy. On US, the microcalfications were also evident as a deeply located non-mass lesion, suspicious for malignancy (BIRADS 4A). Based on these radiology results, preoperative lesion localization and surgical excision were planned.

\section{Lesion Localization}

Both patients were informed about the procedure, and informed consent was obtained from each patient. This study was conducted after approval was obtained from the Institutional Review Board for Breast Diseases. Lesion localization was performed by radiologists within $1 \mathrm{~h}$ before surgery. Image guidance was done by US (Siemens Sonoline Elegra S100, Erlangen, Germany). Under local anesthesia, a 22-gauge spinal needle was placed into the center of the lesion, and $2 \mathrm{ml}(10 \mathrm{mg})$ of ICG solution (ICG-Pulsion $^{\circledR}, 5 \mathrm{mg} / \mathrm{ml}$, Pulsion Medical Systems AG, Munich, Germany) were injected intralesionally (fig. 1, online supplemental). Correct localization was confirmed by US with the help of the dynamic change in echogenicity of the lesion after ICG injection. Because of the deep localization of the lesion within the breast in both cases, a second injection with a smaller dose of ICG solution $(0.2 \mathrm{ml})$ was placed into the subcutaneous tissue projection of the lesion in order to achieve better visualization of the fluorescence during surgery.

\section{ICG Fluorescence-Guided Occult Lesion Excision}

The IC-VIEW system (Pulsion Medical Systems AG) was used for the visualization of ICG-derived fluorescence in the breast tissue. This system consists of a near-infrared laser light source with a wavelength of $760 \mathrm{~nm}$ for the excitation of ICG dye, and a near-infrared-sensitive CCD video camera (Photodynamic Eye, Hamamatsu Photonics Co., distributed by Pulsion Medical Systems AG) for the detection of fluorescence. First, the surgeon identified and marked the site of the skin incision with a suitable pen by observing the area of ICG fluorescence. Under general anesthesia, the patient was placed in a supine position with the arm on the lesion side completely abducted. During surgery, the first assistant held the camera at a distance of 30-50 cm from the breast. Following skin incision, dissection was carried out toward the injected ICG covering the lesion, and the resection margins were defined with fluorescence imaging (figs. 2 and 3, online supplemental). After the lesion was excised, the camera was used to examine the resection bed to verify that there were no residual areas of fluorescence. The surgical margins of the excised specimen were either marked with silk sutures or metallic clips for anatomical orientation. Intraoperative frozen section examination and specimen mammography were performed in both cases in order to confirm the presence of lesion in the resected specimen and that there was no lesion involvement at the surgical margins. The specimen was then returned to the pathology department for histopathologic assessment. In the first case, with invasive cancer, prior to the lesion excision, sentinel lymph node biopsy was carried out with a gamma-detecting probe. In addition to the radioguided technique, the location of the sentinel node was also identified in real time with the near-infrared camera by following the fluorescence of lymphatic stream from the primary lesion site. Following excision, the sentinel nodes ( 2 nodes) showed both fluorescence and high radioactivity. In both cases, the breast lesions were successfully localized and removed surgically. The area of ICG fluorescence corresponded well to the site of the lesion. The overall operative times in the first and second cases were 60 and $35 \mathrm{~min}$, respectively. Following an uneventful postoperative course, both patients were discharged within $24 \mathrm{~h}$. The aesthetic outcome was successful, as affirmed by the patients. The final histopathologic examination confirmed the preoperative diagnosis of invasive ductal cancer in the first case, and revealed ductal carcinoma in situ in the second. There was no tumor involvement at the surgical margins. In the first case where sentinel node biopsy was performed, no metastasis was detected in any of the excised nodes.

\section{Discussion}

To date, several different techniques have been described for the localization of nonpalpable breast lesions, the most common being the introduction of a hooked wire [2]. It is now well documented that wire localization harbors important disadvantages such as wire migration, displacement, patient discomfort, and poor aesthetic outcome [1, 2]. Another method is the intraopearative use of US; however, US cannot 
always detect certain types of lesions, especially microcalcifications [3]. Alternatively, ROLL has been reported to be a better option resulting in easier, more accurate, and rapid removal of these lesions [1-4]. However, this technique requires radioactive material for lesion localization thus it is impractical at institutions where there is no nuclear medicine facility.

ICG is a nontoxic agent and has an optical property to fluoresce when exposed to near-infrared light with a wavelength of $760 \mathrm{~nm}$. Near-infrared light penetrates deeply into living tissues so that the ICG-derived fluorescence can be easily viewed with an infrared-sensitive camera [5, 8]. Since the introduction of ICG fluorescence imaging in breast surgery by Kitai et al. in 2005 [5], this technique has been applied for the intraoperative identification of sentinel lymph nodes in patients with breast cancer. Preliminary data from recent studies has shown that this technique is feasible and accurate with acceptable sensitivity and specificity, comparable to conventional node detection methods [6-9]. Technically, ICGguided technique utilizes subareolar injection of ICG followed by real-time visualization of the lymphatic stream and subsequent sentinel lymph node biopsy guided by a fluorescence imaging system. Inspired by this novel technique, we investigated the usefulness of ICG fluorescence imaging as a guide to the surgical excision of nonpalpable breast cancer.

The presented method, which we termed IFOLL, shares similar technical principles with ICG-guided sentinel node biopsy. However, the key point of IFOLL is that ICG is injected directly into the center of the breast lesion under mammography or US guidance. Subsequently, dissection is carried out and resection margins are defined by observing the fluorescence areas with a near-infrared camera. As in the presented cases with deeply seated breast lesions, in addition to intralesional injection, a much smaller dose of ICG $(0.2 \mathrm{ml})$ can also be injected into the subcutaneous tissue projection of the lesion in order to enhance fluorescence visualization, allowing precise placement of the skin incision. By using this technique, the breast lesions were correctly localized, and the fluorescent area corresponded well to the site of lesion, aiding successful and elegant surgical removal.

The nonpalpable breast lesion in both cases was demonstrable both on mammography and US, and US was the preferred modality for the preoperative localization. This is because US is more practical and less expensive than stereotaxis, and it allows the visualization of every moment of needle insertion [10]. US also gives the radiologist the opportunity to observe the dynamic change in the echogenicity of the lesion caused by the injected ICG dye.

Important advantages of using the IFOLL technique are: i) The location of the skin incision and the resection margins of the breast lesion can be precisely identified by direct visual- ization of ICG; ii) Since no wire or radioactive material is used, it eliminates all wire-related problems and the concerns about radiation dose to patients and hospital staff; iii) The technique only requires collaboration between the radiologists and surgeons, thus, it can also be performed at centers where nuclear medicine facilities are not available. One major disadvantage of this technique is the time limitation for surgical excision. It is reported that the mean time for ICG to arrive at the axilla after subareolar injection is 88.7 seconds [9]. We performed ICG injection $1 \mathrm{~h}$ before surgery; therefore, a major concern was the inability to localize the breast lesion due to lymphatic transport of the dye from the primary lesion site. The 1-h interval period, in fact, allowed ICG to migrate towards the sentinel node, as in the first case where the excised radioactive sentinel nodes were also fluorescent. However, the lymphatic transport did not constitute a problem during excision since most of the injected ICG was found to have remained at the primary site in both cases. As mentioned in the earlier reports [5, 7, 8], another disadvantage is the difficulty of performing excision and fluorescence imaging simultaneously since shadowless light in the operating room must be turned off during fluorescence imaging. Therefore, we had to turn the light on and off during the surgical procedures.

Our limited experience with only 2 cases so far suggests that IFOLL seems to be technically applicable and clinically acceptable for the removal of nonpalpable breast cancer. Further studies assessing its feasibility and validating this technique are required.

\section{Online Supplemental Figures}

Fig. 1. Ultrasonographic appearance of a nonpalpable breast lesion: A hypoechoic mass with irregular margins; B intralesional injection of indocyanine green (ICG) solution with a spinal needle under ultrasound guidance (arrow)

Fig. 2. A During surgery, a near-infrared-sensitive imaging system was used to observe $\mathbf{B}$ the area of indocyanine green (ICG)-derived fluorescence.

Fig. 3. A The resection margins were defined under the guidance of fluorescence imaging; B appearance of the specimen after excision.

To access the online supplemental figures, please refer to www.karger. $\mathrm{com} / \mathrm{DOI}=000336497$.

\section{Conflict of Interest}

The authors have no financial interest in the products presented in this work. 
1 Medina-Franco H, Abarca-Pérez L, García-Alvarez MN, Ulloa-Gómez JL, Romero-Trejo C, Sepúlveda-Méndez J: Radioguided occult lesion localization (ROLL) versus wire-guided lumpectomy for non-palpable breast lesions: a randomized prospective evaluation. J Surg Oncol 2008;97:108-111.

2 Van der Ploeg IM, Hobbelink M, van den Bosch MA, Mali WP, Borel Rinkes IH, van Hillegersberg R: 'Radioguided occult lesion localisation' (ROLL) for non-palpable breast lesions: a review of the relevant literature. Eur J Surg Oncol 2008;34:1-5.

3 Luini A, Zurrida S, Paganelli G, Galimberti V, Sacchini V, Monti S, Veronesi P, Viale $\mathrm{G}$, Veronesi U: Comparison of radioguided excision with wire localization of occult breast lesions. Br J Surg 1999;86:522-525.

4 Aydogan F, Ozben V, Celik V, Uras C, Tahan G, Gazioglu E, Cengiz A, Ferahman M, Cercel A, Yilmaz MH, Halac M, Unal H: Radioguided occult lesion localization (ROLL) for non-palpable breast cancer: a comparison between day-before and same-day protocols. Breast 2010;19:226-230.

5 Kitai T, Inomoto T, Miwa M, Shikayama T: Fluorescence navigation with indocyanine green for detecting sentinel lymph nodes in breast cancer. Breast Cancer 2005;12:211-215.

6 Tagaya N, Aoyagi H, Nakagawa A, Abe A, Iwasaki Y, Tachibana M, Kubota K A novel approach for sentinel lymph node identification using fluorescence imaging and image overlay navigation surgery in patients with breast cancer. World J Surg 2011;35:154-158.

7 Hirche C, Murawa D, Mohr Z, Kneif S, Hünerbein M: ICG fluorescence-guided sentinel node biopsy for axillary nodal staging in breast cancer. Breast Cancer Res Treat 2010;121:373-378.

8 Tagaya N, Yamazaki R, Nakagawa A, Abe A, Hamada K, Kubota K, Oyama T: Intraoperative identification of sentinel lymph nodes by near-infrared fluorescence imaging in patients with breast cancer. Am J Surg 2008;195:850-853.

9 Ogasawara Y, Ikeda H, Takahashi M, Kawasaki K, Doihara H: Evaluation of breast lymphatic pathways with indocyanine green fluorescence imaging in patients with breast cancer. World J Surg 2008;32:1924-1929.

10 Feggi L, Basaglia E, Corcione S, et al.: An original approach in the diagnosis of early breast cancer: use of the same radiopharmaceutical for both non-palpable lesions and sentinel node localisation. Eur J Nucl Med 2001;28: $1589-1596$. 